\title{
$\mathrm{CCFL}$ 전극의 플라즈마 처리에 관한 연구
}

\author{
박현식 ${ }^{*}$ \\ ${ }^{1}$ 한경대학교 전자공학과
}

\section{Study on Plasma Treatment of electrode for CCFL}

\author{
Hyun Sik, Park ${ }^{1 *}$ \\ ${ }^{1}$ Dept. Electronic Eng., Hankyong National University
}

요 약 $\mathrm{CCFL}$ (Cold Cathode Fluorescent Lamp)는 LCD의 BLU와 특수조명용으로 널리 활용되고 있다. CCFL 제조공 정에 있어 $\mathrm{CCFL}$ 전극 산화막이 형성되어 솔더 불량을 가져오기 때문에 산화 막 제거가 필요하다. 본 논문에서는 $\mathrm{CCFL}$ 전극 산화 막 제거를 위하여 플라즈마 처리를 수행하였다. 플라즈마 처리 최적 공정을 확보하기위하여 면 저 항, $\mathrm{XRD}, \mathrm{AFM}$, 솔더링 테스트 등의 분석이 진행되었다. 플라즈마 최적 공정 조건인 사용전력 $600 \mathrm{~W}$ 와 처리시간 70 초에서 최소의 면 저항과 최대의 솔더 피복 비율이 측정되었다. 이와 같은 현상은 플라즈마 처리로 구리 산화 막 제 거에 기인한 것으로 확인되어 플라즈마를 이용한 전극 산화 막 제거 공정은 $\mathrm{CCFL}$ 전극 처리 공정에 활용이 기대된다.

\begin{abstract}
CCFL(Cold Cathode Fluorescent Lamp)for BLU of LCD and special lighting has been widely utilized. The removal of oxide film formed on electrode of CCFL in manufacturing process is required .In this pape Plasma treatment was carried out to remove the oxide film. To ensure the optimum process, the analysis of sheet resistance, XRD, AFM and solder test was conducted. A minimum sheet resistance and the maximum percentage of the solder coverage ratio were measured in optimal process conditions such as plasma power consumption $600 \mathrm{~W}$ and processing time of 70 seconds. As the plasma treatment is confirmed to be due to removal of copper oxide, this process is expected to be used as a treatment of electrode for CCFL.
\end{abstract}

Key Words : CCFL(Cold Cathode Fluorescent Lamp), Electrode treatment, BLU(Back Light Unit)

\section{1. 서론}

CCFL(Cold Cathode Fluorescent Lamp)은 LCD(Liquid Crystal Display)의 BLU(Back Light Unit) 같은 특수 조명 용으로 사용되고 있다[1,2]. CCFL 제조 공정은 유리 내면 에 형광체를 코팅하고 전극을 융착하여 제조한다. 이때 $\mathrm{CCFL}$ 융착 공정은 고온공정으로서 구리 전극 표면에 산 화막이 발생하며 전극 표면의 산화 막은 솔더(Solder)의 젖음성을 저하시켜 접합 불량을 가져온다[3].

즉 $\mathrm{CCFL}$ 구리 전극의 산화 막의 존재는 그림 1 과 같 이 $\mathrm{CCFL}$ 전극의 솔더링(Soldering) 공정에서 솔더의 접 합 불량을 유발시키는 문제점을 지니고 있어 산화 막 제 거 공정이 반드시 필요하게 된다.

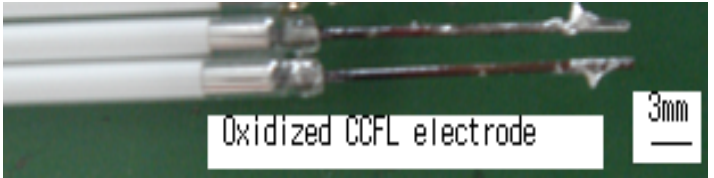

[그림 1] 산화된 CCFL 전극.

$\mathrm{CCFL}$ 구리 전극의 산화 막 제거를 위하여 습식방법인 산세 처리 공정으로 진행하고 있으나 환경 문제를 발생 시키고 있다. 플라즈마를 이용한 표면처리는 전자 패키 징(Electronic Packaging)과 집적회로 배선 전극 처리 방 법으로 보고[4,5]된 바 있다. PBGA(Plastic Ball Grid Array)표면의 본딩성(Bondability)과 부착(Adhesion)특성 개선을 위한 플라즈마 처리 방법이 보고[4]된 바 있으며, 수소 플라즈마 방법으로 집적회로 배선에 사용되는 구리

본 연구는 2009년도 한경대학교 교비 파견 연구비의 지원에 의한 것임.

"교신저자 : 박현식(hspark@hknu.ac.kr)

접수일 11년 01월 03일수정일 11년 02월 09일

게재확정일 11 년 03 월 10 일 
전극 표면에 형성된 구리 산화 막의 제거도 보고[5]된 바 있다.

본 연구에서는 건식 방법인 플라즈마 공정을 이용하여 $\mathrm{CCFL}$ 전극 저리를 수행하여 구리 전극의 산화 막 제거 에 대한 연구를 수행하였다. 특히 본 연구에서는 진공 챔 버(Chamber)를 사용하지 않고 생산라인에 인라인 적용이 가능한 상압 플라즈마(Atmospheric Pressure Plasma) 공 정을 이용하였다.

실제 사용되는 직경 $3 \mathrm{~mm}$ 의 $\mathrm{CCFL}$ 구리 전극 직경은 $0.6 \mathrm{~mm}$ 로서 산화 막의 분석과 특성 해석에는 제약을 받 게 되어 본 연구에서는 $\mathrm{CCFL}$ 융착 공정과 동일 조건에 서 산화 처리된 평판형 구리 시편을 사용하여 최적화된 플라즈마 전극처리 조건을 설정하였고 이를 바탕으로 $\mathrm{CCFL}$ 의 구리 전극을 대상으로 플라즈마 전극처리 하였 다.

\section{2. 실험방법}

산화된 $\mathrm{CCFL}$ 구리 전극의 플라즈마 최적 공정 조건을 확보하기위하여 위하여 CCFL 융착 공정에서 산화 처리 한 평판 형 구리 시편(면적 $75 \mathrm{~mm}^{2}$, 두께 $1 \mathrm{~mm}$ )을 준비하여 상압플라즈마로 환원 처리하고 표면 분석을 수행하였다.

상압 플라즈마 발생은 글로우 방전(Glow Discharge) 플라즈마 발생 모듈을 이용하였다. 플라즈마 발생모듈은 플라즈마의 발생을 위해 전기 에너지를 공급하는 플라즈마 전원 전극, 플라즈마 전원전극에 마주보게 위치하는 접지 전극, 전원 전극과 접지 전극의 중간에 위치하는 유전체 막, 전원 전극과 접지 전극의 사이에 플라즈마 발생을 위한 가스 를 공급하는 가스 공급 노즐, 전원 전극에 플라즈마 발생을 위한 전기 에너지를 공급하는 RF 전원 장치로 그림2와 같이 구성하였고 그림 3과 같이 상압 플라즈마 상태를 확보할 수 있었다. 제작된 플라즈마 발생 모듈의 사용전력은 $500 \mathrm{~W}$ $700 \mathrm{~W}$ 범위로 제어하였다. 사용된 가스는 $10 \ell / \mathrm{min}$ 의 아르 곤 가스,와 고량의 질소 및 수소가스로 구성된 혼합가스를 사용하였다. 온도계측에는 표준 수은 온도계와 적외선온도 계로 측정하였다.

플라즈마 최적 조건을 도출하기위하여 표면 저항 측정 을 위한 4-point probe, 플라즈마 처리 전후의 상 분석 측 정을 위한 $\mathrm{Cu}$ 타겟의 $\mathrm{XRD}(\mathrm{X}$-Ray Diffractometer), 표면상 태 측정을 위한 $\mathrm{AFM}$ (Atomic Force Microscope) 및 접촉 각 테스트가 수행되었다.

$\mathrm{CCFL}$ 전극을 플라즈마 처리하고 솔더링 테스트를 하 였다. 솔더링 테스트는 $240^{\circ} \mathrm{C}$ 로 유지되는 $\mathrm{Sn}$ 계 $(\mathrm{Bi}-\mathrm{Cu}-$ $\mathrm{In}-\mathrm{Sb}-\mathrm{Sn})$ 의 솔더를 이용하였으며, 리드선 형태의 전극에
솔더링 정도를 비교하기위하여 솔더 피복 비율(Solder Coverage Ratio)로 솔더링의 결과를 평가하였다.

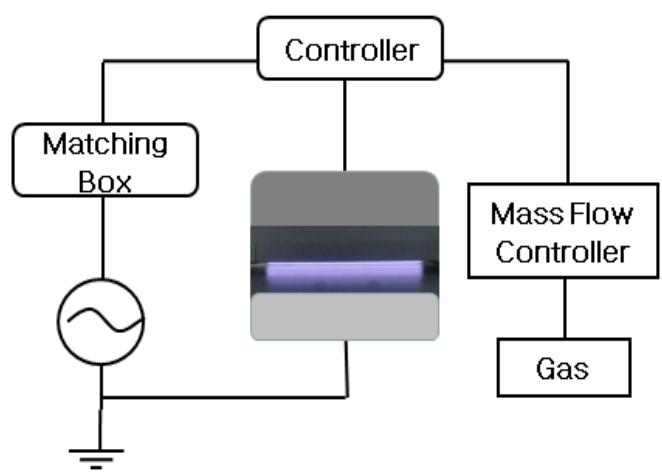

[그림 2] 플라즈마 발생모듈 구성도.

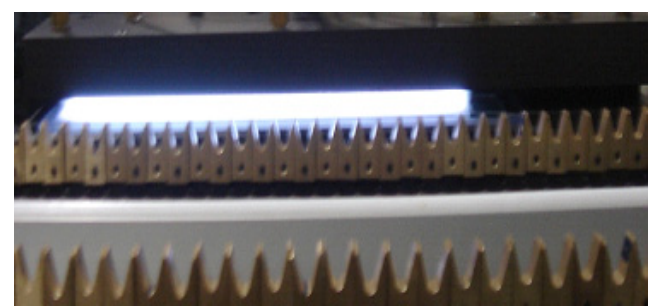

[그림 3] 본 연구에 적용된 Ar계 혼합 가스 분위기의 상압 플라즈마.

\section{3. 결과 및 검토}

\section{1 플라즈마 공정 조건}

아르곤 혼합가스 분위기에서 처리시간 80 초의 조건에서 플라즈마 사용전력에 따른 면 저항 측정 결과는 그림 4 와 같 다. 측정결과 면 저항은 그림 4 와 같이 $600 \mathrm{~W}$ 이상의 범위에 서 면 저항이 가장 낮은 상태로 측정되었다.

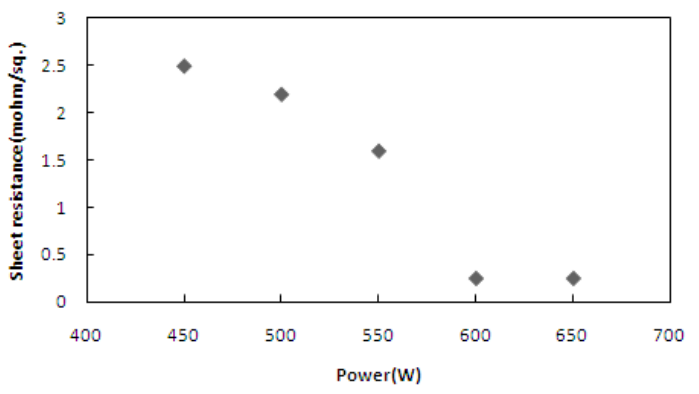

[그림 4] 플라즈마 사용전력에 따른 면 저항 값 변화. 
사용전력 $600 \mathrm{~W}$ 에서 플라즈마 공정 온도를 측정한 결과 그림 5 와같이 공정온도가 $250^{\circ} \mathrm{C}$ 로 일정하게 유지되었으며 본 연구의 공정 온도 $250^{\circ} \mathrm{C}$ 는 M. R. Baklanov 등도 구리 산화 막 제거 온도로 제시한 온도 범위에 해당된다[5].

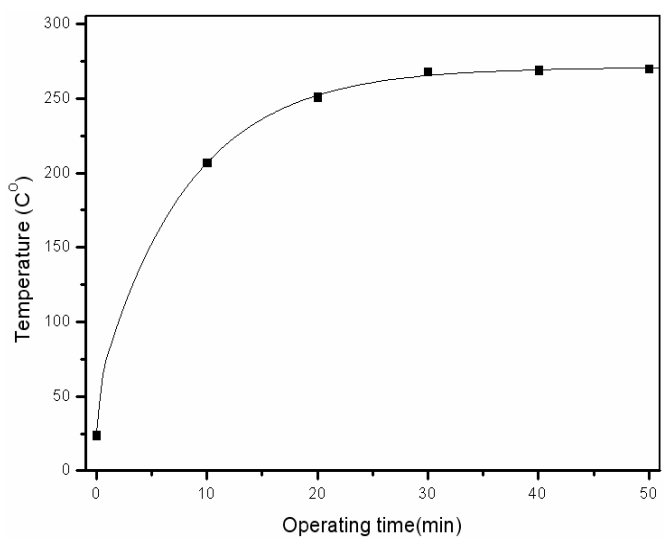

[그림 5] 플라즈마 공정온도.

플라즈마 처리시간에 따른 면 저항 측정 결과 그림 6과 같 이 70 초 이상에서는 면 저항이 최소로 나타나고 있음을 확 인할 수 있었다.

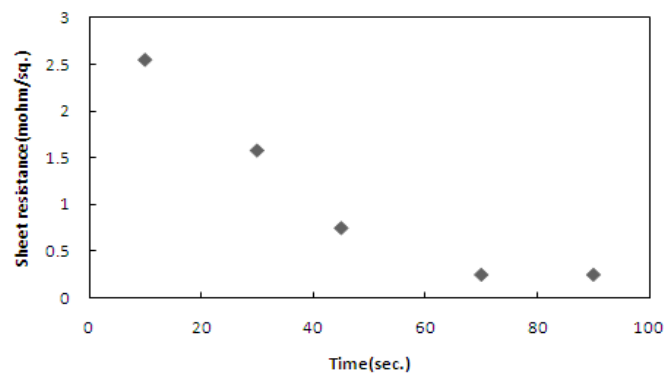

[그림 6] 플라즈마 처리 시간에 따른 면 저항 값 변화.

플라즈마 처리 조건으로 사용전력 $600 \mathrm{~W}$ 와 처리시간 70 초 이상에서 가장 낮은 면 저항 값이 측정되었고, 측정된 면 저항 값은 습식 공정인 산세 처리에서 측정값과 거의 일치 하였다. 따라서 이들 플라즈마 조건에서 산화막이 제거된 것으로 추정되었고 이를 확인하기위하여 XRD와 $\mathrm{AFM}$ 을 이용하여 표면 분석을 하였다.

\section{2 플라즈마 처리 전후의 표면분석}

그림 7은 플라즈마 처리 전의 XRD 분석결과이다. 분석 결과 $\mathrm{Cu}, \mathrm{CuO}, \mathrm{Cu}_{2} \mathrm{O}$ 의 상들이 관찰되었다. 구리 산화막인 $\mathrm{CuO}$ 와 $\mathrm{Cu}_{2} \mathrm{O}$ 는 $\mathrm{CCFL}$ 융착 공정에서 구리 표면에서 산화되 어 형성된 것으로 간주되었다.

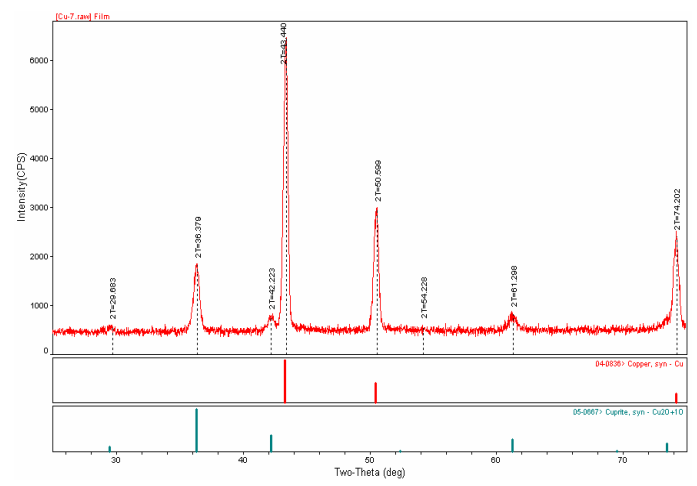

[그림 7] 플라즈마 처리 전 시편의 XRD 분석 결과.

그림8은 사용전력 $600 \mathrm{~W}$ 와 처리시간 70 초로 플라즈마 처리된 XRD 분석 결과이다. 분석결과 산화막인 $\mathrm{CuO}$ 가 관 찰되지 않았고 이는 플라즈마 처리 과정에서 $\mathrm{CuO}$ 가 제거된 것이다[6-8]. 플라즈마 처리 이후에 잔류하고 있는 $\mathrm{Cu}_{2} \mathrm{O}$ 는 플라즈마처리 이후상온에서 형성된 산화막으로간주되었다.

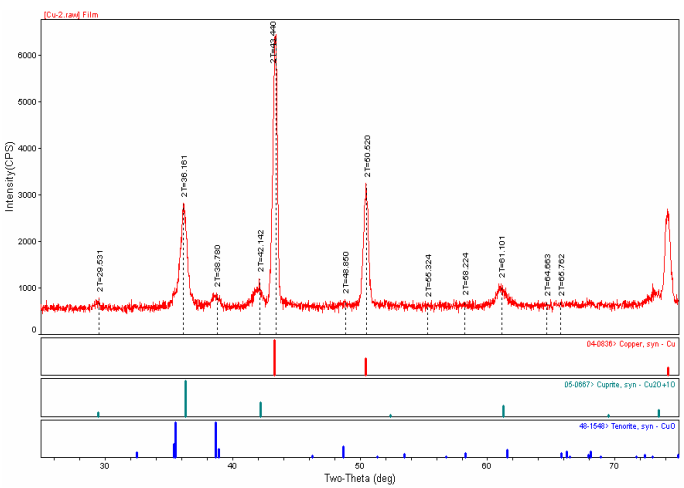

[그림 8] 플라즈마 처리 후 시편의 XRD 분석 결과.

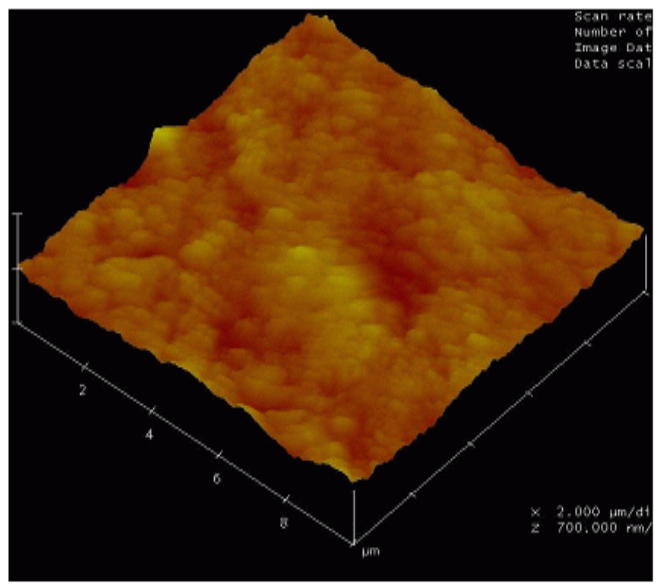

[그림 9] 플라즈마 처리 전 시편의 $\mathrm{AFM}$ 분석 결과. 
그림 9는 플라즈마 처리전의 산화 막 상태 표면의 AFM 분석결과이고 그림 10 은 사용전력 $600 \mathrm{~W}$ 와 처리시간 70 초 로 플라즈마 처리된 표면의 $\mathrm{AFM}$ 분석결과이다.

산화막이 형성되어 있는 표면과 플라즈마 처리 후의 구 리 표면을 비교하면, 평균 거칠기가 $370.97 \AA$ 에서 $354.48 \AA$ 으로 $16.49 \AA$ 감소한 것을 확인할 수 있다.

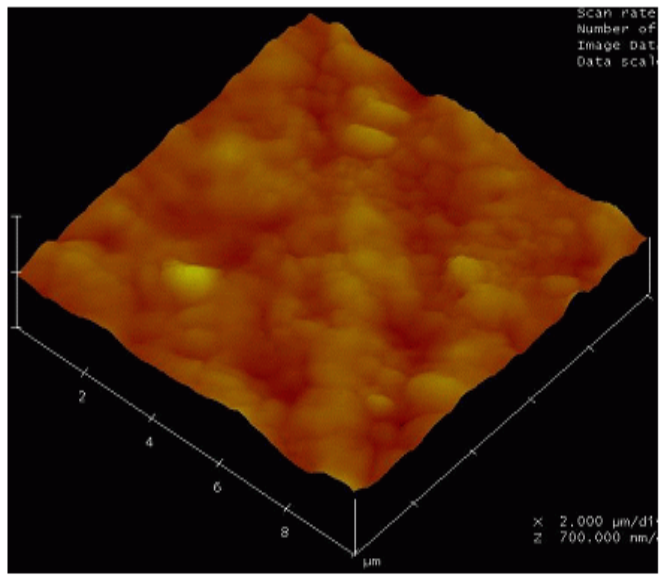

[그림 10] 플라즈마 처리 후 시편의 $\mathrm{AFM}$ 분석 결과.

\section{2 플라즈마 처리된 $\mathrm{CCFL}$ 전극의 솔더테스 트결과}

$\mathrm{CCFL}$ 전극의 사용전력에 따른 솔더링 테스트 결과 그림 11 과 같이 처리시간 80 초 조건으로 사용전력 $600 \mathrm{~W}$ 이상에 서 솔더 피복 비율(Solder Coverage Ratio)이 $100 \%$ 로 측정 되었다. 이 결과는 $600 \mathrm{~W}$ 이상에서 플라즈마 처리된 구리시 편의 면 저항이 최소로 되는 경향과 같다. 즉 플라즈마 처리 로 앞에서 확인된 바와 같이 구리 산화막이 제거된 결과이다.

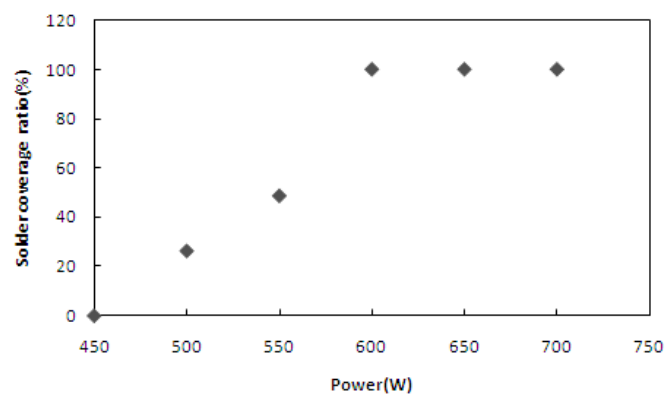

[그림 11] 플라즈마 사용전력에 따른 솔더 피복 비율.

플라즈마 처리시간에 따른 솔더 피복 비율을 측정한 결 과 그림 12 와 같이 70 초 이상에서 솔더 피복 비율이 $100 \%$ 로 측정되었다. 이결과는 70 초 이상에서 면 저항이 최소로 나
타나는 결과와 유사한 결과이다.

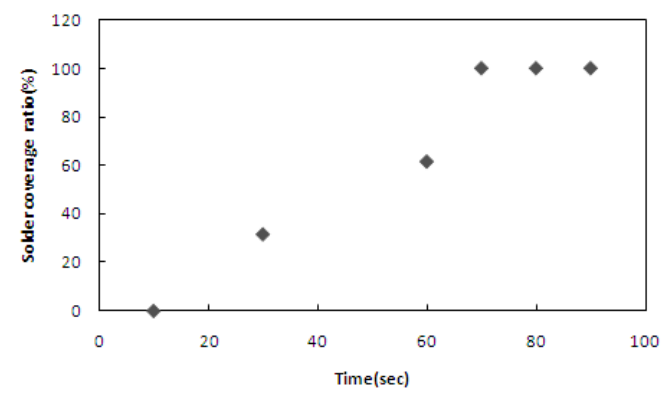

[그림 12] 플라즈마 처리시간 에 따른 솔더 피복 비율.

플라즈마 사용전력 $600 \mathrm{~W}$, 처리시간 70 초 조건에서 그 림 13과 같이 솔더 피복 비율이 최대로 나타남을 확인할 수 있었고 이 조건이 $\mathrm{CCFL}$ 구리 전극의 플라즈마 처리 최적 조 건으로 사료되었다.

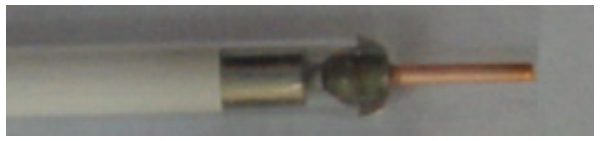

(a)

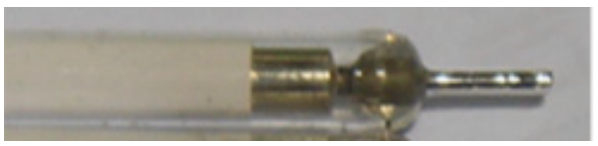

(b)

[그림 13] 플라즈마 처리 후 CCFL(직경 3mm).

(a) 산화 막 제거된 CCFL 전극.

(b) 솔더 피복된 CCFL 전극.

플라즈마 최적 조건에서 양호한 특성이 관찰되는 것은 구리 산화막이 제거된 것에 기인하는 것으로 확인되었다. 솔더 피복 비율측정 결과와 면 저항 측정 결과는 높은 연관 성을 나타내어 면 저항이 적을수록 솔더 피복 비율도 높게 측정되었다.

\section{4. 결론}

CCFL 제조공정에서 발생하는 산화 막을 제거하기위 하여 플라즈마 처리가 수행되었고, 플라즈마 처리 전후 측정 결과 다음과 같은 결론을 얻을 수 있었다. 본 연구 의 플라즈마 최적조건으로서 플라즈마 사용전력 $600 \mathrm{~W}$ 와 처리시간 70 초 조건에서 최소의 면 저항 값이 측정되었 고, $\mathrm{CCFL}$ 전극 솔더 피복 비율은 최대로 측정되었다. 이 
와 같은 원인은 XRD 분석결과로부터 구리 산화막이 플 라즈마 처리로 제거된 것에 기인함을 확인하였다. 따라 서 플라즈마 처리는 CCFL의 구리 전극 산화 막 제거에 유효하게 적용될 수 있다.

\section{참고문헌}

[1] Chang, Yong N.; Lin, Ching C.; Chan, Shun Y.; Lin, Shian N.; Lin, Jia C. "Development of lighting source with CCFL in T8-tube", Power Electronics Conference (IPEC) 2010, pp.390-397, 2010.

[2] Uetsuki, T.; Kitamoto, R.; Takeda, Y.; Fukumasa, O., "A Study on the relationship between electrode materials and characteristics of CCFL", Plasma Science, 2006.ICOPS2006.pp.193-193,2006.

[3] Lei Zhang; Guangwei Sun; Li Li; Shang, J.K," Effect of Copper Oxide Layer on Solder Wetting Temperature under a Reduced Atmosphere", Electronic Packaging Technology, 2007.ICEPT pp.1-7, 2007.

[4] Charles Lee, Tan Check-Eng Rachel, Ong Wai-Lian Jenny, R. Gopalakrishnan, Khine Nyunt, Andrew Wong,, "Plasma cleaning for plastic ball grid array; A study on surface cleanliness, wire bondability and adhesion", Proceedings of 6th IPFA 1997, pp.50-55, 1997.

[5] Baklanov, M. R. Shamiryan, D. G. Tokei, Zs. Beyer, G. P. Conard, T. Vanhaelemeersch, S. Maex, K., "Characterization of $\mathrm{Cu}$ surface cleaning by hydrogen plasma", Journal of Vacuum Science \& Technology B: Microelectronics and Nanometer Structures, Vol.19, 4, pp.1201-1211, Jul., 2001.

[6] Belmonte, T. Thiebaut, J. M. Michel, H. Cardoso, R. P. Maliska, A., "Cuprous-Cupric Oxide Films on Copper", Journal of Vacuum Science \&Technology A: Vacuum, Surfaces, and Films, Volume: 20 Issue: 4, pp 1347-1352, Jul 2002

[7] Yasushi Sawada, Hiroshi Tamaru, Masuhiro Kogoma, Motoaki Kawase and Kenji Hashimoto, "The reduction of copper oxide thin films with hydrogen plasma generated by an atmospheric-pressure glow discharge" Journal of Physics D: Applied Physics, Volume 29, Number 10 PP2539,1996.

[8] Jose' A. Rodriguez ,Jae Y. Kim a,Jonathan C. Hanson, Manuel Pe'rez and Anatoly I. Frenkel, "Reduction of $\mathrm{CuO}$ in H2", Catalysis Letters Vol. 85, Nos.3.4, pp.247-254, February 2003.

\section{박 현 식(Hyun-Sik Park)}

[정회원]

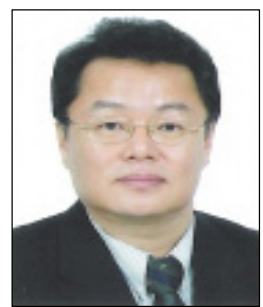

- 1983년 2월 : 인하대학교 재료공 학부(공학사)

- 1985년 2월 : 서울대학교 재료공 학부(공학석사)

- 1987년 1989년 : 일본 Kyoto 대학대학원 특별연구원

- 1990년 2월 : 서울대학교 재료공 학부(공학박사)

- 1991년 : 쌍용중앙연구소 전자재료개발실 선임연구원

- 1992년 1월 1996년 8월 : KETI 부품개발3팀장

- 1996년 9월 현재 : 한경대학교 전자공학과 정교수

- 2002년 2003년 : 미국Colorado대학 NSF센터 방문교 수

\section{<관심분야>}

전자부품(전자세라믹, 반도체소자, 반도체공정, 에너지소 자, 디스플레이, 센서) 